Jurnal Pemberdayaan: Publikasi Hasil Pengabdian kepada Masyarakat

Vol. 2, No. 3, Desember 2018, Hal. 471-478

ISSN: 2088 4559; e-ISSN: XXXX-XXXX

DOI:

\title{
PENERAPAN PROGRAM RUMAH RAMAH SAMPAH PADA KOMUNITAS KALIJAWI
}

\author{
Surahma Asti Mulasari \\ Universitas Ahmad Dahlan Yogyakarta \\ Email : surahma.mulasari@ikm.uad.ac.id
}

\begin{abstract}
ABSTRAK
Dilihat dari sumbernya, sektor rumah tangga termasuk dalam sektor yang paling besar menyumbang produksi sampah. Oleh karena itu, salah satu cara yang efektif untuk mengurangi jumlah timbunan sampah yaitu menyadarkan baik individu maupun keluarga untuk memperhatikan alat atau barang yang mereka pakai sehingga sampah dapat diminimalisir. Oleh karena itu, perlu adanya edukasi lebih lanjut minimal pada tingkat keluarga mengenai bagaimana cara mengurangi produksi sampah baik melalui cara 3R (Reduce, Reuse, Recycle) maupun menggunakan cara-cara lain yang mudah diterapkan di setiap rumah untuk mengurangi sampah yang dihasilkan. Tujuan dari kegiatan ini adalah untuk memberi edukasi tentang upaya-upaya yang dapat dilakukan untuk mengurangi produksi sampah atau memanfaatkan timbunan sampah pada setiap rumah. Metode yang digunakan adalah melalui ceramah (workshop) dan pelatihan, tanya jawab serta diskusi permasalahan tentang rumah ramah sampah. Sasaran pengabdian yaitu Ibu-ibu Komunitas Kalijawi, yang memiliki respon baik terhadap program yang sudah dilaksanakan. Pada saat kegiatan pengabdian dilasanakan, tamu undangan hadir dan berpartisipasi aktif selama proses workshop berlangsung.
\end{abstract}

Kata Kunci: Rumah, Ramah, Sampah

\begin{abstract}
Viewed from the source, the household sector was included in the largest sector contributing to waste production. Therefore, one effective way to reduce the amount of waste generation was to make every family and individual aware of the tools or items they use so that the waste formed can be minimized. Therefore, there was a need for further education at least at the family level on how to reduce waste production either by means of $3 R$ (Reduce, Reuse, Recycle) or use other methods that were easy to implement in each house to reduce the waste produced.

The purpose of this activity was to educate on efforts that can be made to reduce waste production or utilize waste generation in each house. The method used is through lectures (workshops) and training, question and answer and discussion of issues about garbage-friendly homes. The target of the service was the Ladies and Gentlemen, who have a good response to the programs that have been implemented. When the service activities were held, invited guests attended and actively participated during the workshop process.
\end{abstract}

Keywords: Home, Friendly, Waste 


\section{PENDAHULUAN}

Indonesia sebagai negara berkembang dan salah satu negara dengan penduduk terbesar di dunia memiliki satu masalah besar yaitu sampah. Dalam lingkup negara, sampah menjadi tantangan tersendiri karena setiap tahun jumlahnya meningkat sehingga pemerintah bisa dibilang kewalahan untuk mengatasinya. Jumlah produksi sampah yang terus meningkat menjadi satu poin penting yang harus diperhatikan karena jika tren tersebut terus berlangsung akan menimbulkan efek negatif baik untuk masyarakat maupun lingkungan.

Sampah-sampah tersebut berasal dari berbagai kegiatan seperti kegiatan pertanian, pasar, rumah tangga, hiburan dan industri. Sampah yang dihasilkan dalam jumlah yang besar. Sampah apabila terlambat ditangani, maka akan menghasilkan sampah yang besar pula. Sampah yang dihasilkan dari kegiatan rumah tangga tersebut disebut sebagai limbah domestik atau sampah masyarakat (Sudiran, 2005).

Mengelola sampah membutuhkan peran aktif masyarakat, terutama untuk mengurangi jumlah sampah, memilah jenis sampah hingga berupaya menjadikan sampah lebih bermanfaat. Keterlibatan masyarakat dalam proses pengelolaan sampah dengan basis pertisipasi aktif masyarakat terdiri dari tahapan proses yaitu, mengupayakan agar sampah dikelola, dipilah dan diproses, dapat diawali dari lingkungan rumah tangga, upaya ini akan mengurangi jumlah timbunan sampah yang harus dikelola di TPS (Suwerda, 2012).

Pengelolaan sampah adalah suatu kegiatan pengendalian sampah mulai dari tempat penyimpanan sementara, pengumpulan, pengangkutan, pengolahan, sampai pembuangan akhir dengan menggunakan teknik sesuai prinsip-prinsip kesehatan masyarakat atau kesehatan lingkungan. Kegiatan pengelolaan ini menyangkut administrasi, manajemen, aspek legal, tekhnologi tepat guna, dan peran serta masyarakat. Pengelolaan sampah juga berkaitan dengan aspek politik, ekonomis, sosiologis atau antropologis, demografis, geografis atau topografis, ekologi, dan amdal (Budiman, 2010).

Dari data observasi pada bulan Desember 2012, Wilayah Kota Yogyakarta merupakan penghasil sampah terbesar dari empat kabupaten yang ada disekitarnya. Setiap harinya Kota Yogyakarta menyumbangkan sampahnya sebanyak 67 persen sampah dari total 76 persen sampah yang dibuang ke TPSA Piyungan Bantul Yogyakarta. Tingginya jumlah sampah yang dihasilkan oleh masyarakat Kota Yogyakarta dikarenakan beragam aktivitas yang padat seperti berdagang, bertani, kantor, dan sebagainya. Banyaknya variasi kegiatan dan aktivitas yang ada di Kota Yogyakarta menyebabkan setiap harinya kecenderungan sampah dihasilkan oleh masyarakat semakin bervariasi dan beragam. Sampah yang jika terus 
menerus dihasilkan tidak diolah dengan baik, maka hal ini akan menjadi masalah bagi masyarakat Kota Yogyakarta. Sampah yang tidak tertangani atau tidak diolah dengan baik akan menimbulkan banyak penyakit, pencemaran dan lain sebagainya.

Dilihat dari sumbernya, sektor rumah tangga termasuk dalam sektor yang paling besar menyumbang produksi sampah. Oleh karena itu, salah satu cara yang efektif untuk mengurangi jumlah timbulan sampah yaitu menyadarkan setiap keluarga maupun setiap individu untuk memperhatikan alat atau barang yang mereka pakai sehingga sampah yang terbentuk dapat diminimalisir. Oleh karena itu, perlu adanya edukasi lebih lanjut minimal pada tingkat keluarga mengenai bagaimana cara mengurangi produksi sampah baik melalui cara 3R (Reduce, Reuse, Recycle) maupun menggunakan cara-cara lain yang mudah diterapkan di setiap rumah untuk mengurangi sampah yang dihasilkan.

\section{METODE}

Metode yang diterapkan dalam program kegiatan pengabdian masyarakat ini adalah dengan metode ceramah yakni berupa kegiatan workshop, diskusi dan tanya jawab serta kegiatan pelatihan. Materi yang disajikan berkaitan dengan rumah ramah sampah, langkahlangkah konkrit, aplikatif, mudah diterapkan dan tidak memakan banyak biaya untuk menciptakan sebuah konsep rumah ramah sampah. Kegiatan workshop dilaksanakan pada hari Ahad, 23 September 2018 pada pukul 08.00-13.00 WIB. Sedangkan kegiatan pelatihan dilaksanakan pada hari Ahad, 30 September 2018. Sasaran kegiatan pengabdian ini adalah Ibu-ibu Komunitas Kalijawi.

\section{HASIL, PEMBAHASAN, DAN DAMPAK}

Kegiatan pengabdian telah berjalan dengan baik dan lancar. Sasaran pengabdian yaitu Ibu-ibu Komunitas Kalijawi memiliki respon yang baik terhadap program yang sudah dilaksanakan. Pada saat kegiatan pengabdian dilaksanakan, tamu undangan hadir dan berpartisipasi aktif selama proses workshop berlangsung. 


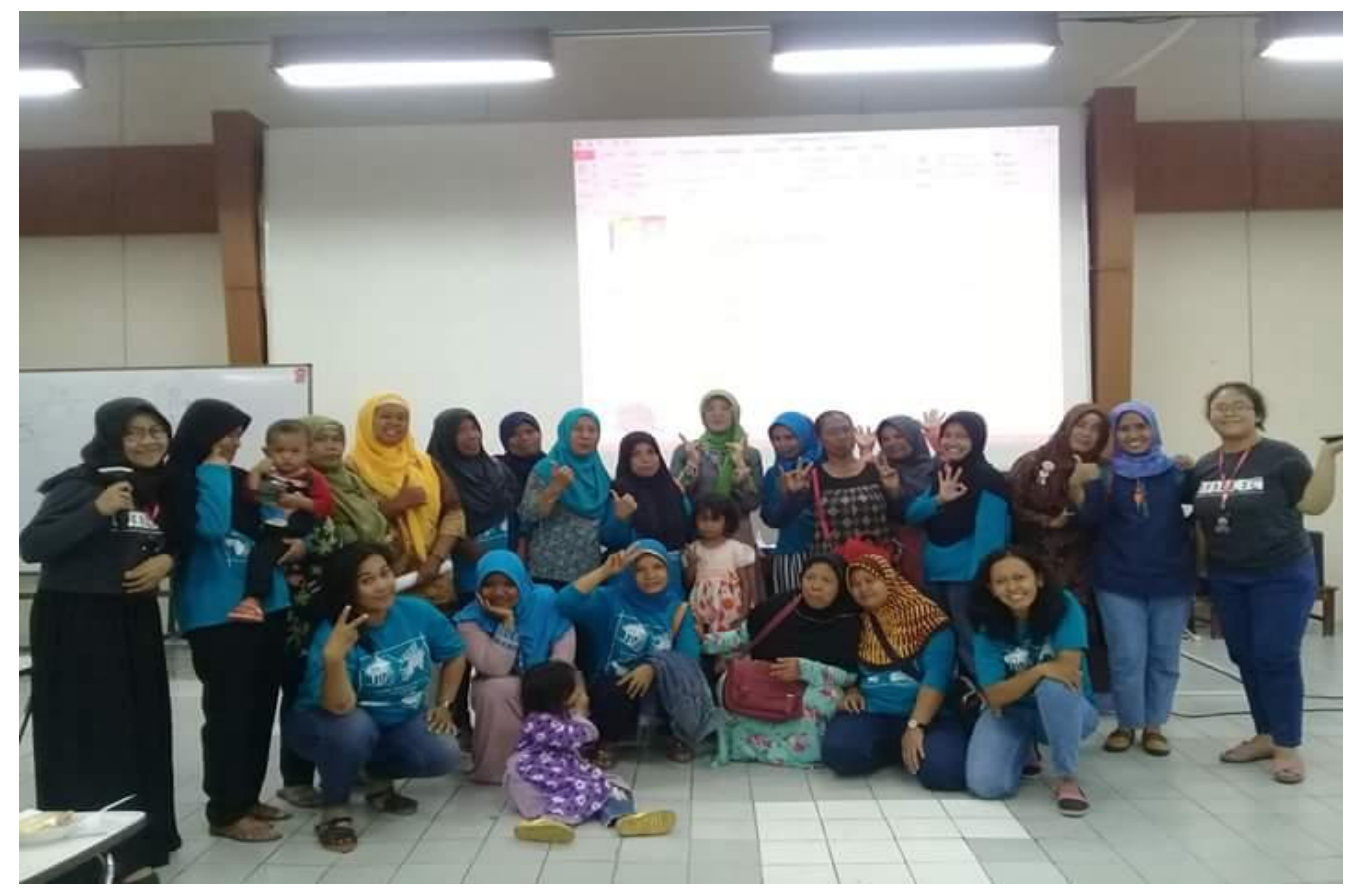

Gambar 1. Foto bersama setelah kegiatan workshop

Dalam pelaksanaan kegiatan workshop, peserta (Ibu-ibu Komunitas Kalijawi) memberikan respon yang positif, mereka terlihat sangat antusias dengan kegiatan workshop ini karena kegiatan ini dapat menambah wawasan Ibu-ibu khususnya tentang rumah ramah sampah, langkah-langkah konkrit, aplikatif, mudah diterapkan dan tidak memakan banyak biaya untuk menciptakan sebuah konsep rumah ramah sampah.

Hal ini dapat dilihat bahwa pada saat kegiatan workshop berlangsung, terjadi komunikasi dua arah, ibu-ibu aktif dalam bertanya tentang hal-hal yang mereka ingin tahu. Ibu-ibu dan narasumber saling berdiskusi mengenai permasalahan-permasalahan yang terjadi saat ini. Diharapkan dengan adanya respon yang positif ini, ibu-ibu dapat menerapkan ilmu yang mereka peroleh serta dapat berpartisipasi menerapkan konsep rumah ramah sampah.

Nuraeni dkk. (2017) mengatakan bahwa sikap merupakan faktor yang mempengaruhi seseorang dalam melakukan suatu tindakan atau perilaku. Salah satu faktor yang mempengaruhi sikap seseorang adalah pendidikan, pengetahuan dan pengalaman. Untuk mendapatkan perilaku yang baik, maka faktor-faktor yang mempengaruhinya juga harus baik. Untuk meningkatkan perilaku pencegahan dan perawatan hipertensi, maka sikap dan faktor lain juga harus ditingkatkan. Salah satu upaya untuk meningkatkannya adalah dengan kegiatan pembelajaran melalui media pembelajaran.

Pemberian informasi dan edukasi melalui media pembelajaran, salah satunya dengan kegiatan penyuluhan kesehatan. Pada dasarnya penyuluhan kesehatan identik dengan pendidikan kesehatan karena keduanya berorientasi terhadap perubahan perilaku yang 
diharapkan yaitu perilaku sehat. Sehingga mempunyai kemampuan mengenali masalah kesehatan dirinya, keluarga, dan kelompok dalam meningkatkan kesehatannya. Metode yang dapat digunakan dalam memberikan penyuluhan kesehatan yaitu dengan metode ceramah. Metode ceramah adalah suatu cara dalam menerangkan dan menjelaskan suatu ide, pengertian atau pesan secara lisan kepada sekelompok sasaran sehingga memperoleh informasi mengenai kesehatan (Notoatmodjo, 2010).

Kegiatan workshop mengenai rumah ramah sampah ini merupakan salah satu kegiatan promosi kesehatan, yang merupakan proses memberikan kemampuan pada masyarakat dalam hal ini adalah Ibu-ibu Komunitas Kalijawi, untuk meningkatkan dan memperbaiki kesehatan khususnya dengan menerapkan konsep rumah ramah sampah. Saat ini, banyak masyarakat yang belum mengetahui mengenai konsep rumah ramah sampah. Oleh karena itu, diperlukan suatu informasi dan edukasi mengenai program rumah ramah sampah kepada seluruh masyarakat. Sulistyorini dkk. (2015) dalam penelitiannya mengatakan bahwa sampah yang selama ini kita buang begitu saja, ternyata masih dapat diolah kembali antara lain dalam bentuk kerajinan yang bernilai ekonomi, berita rasa seni dan unik.

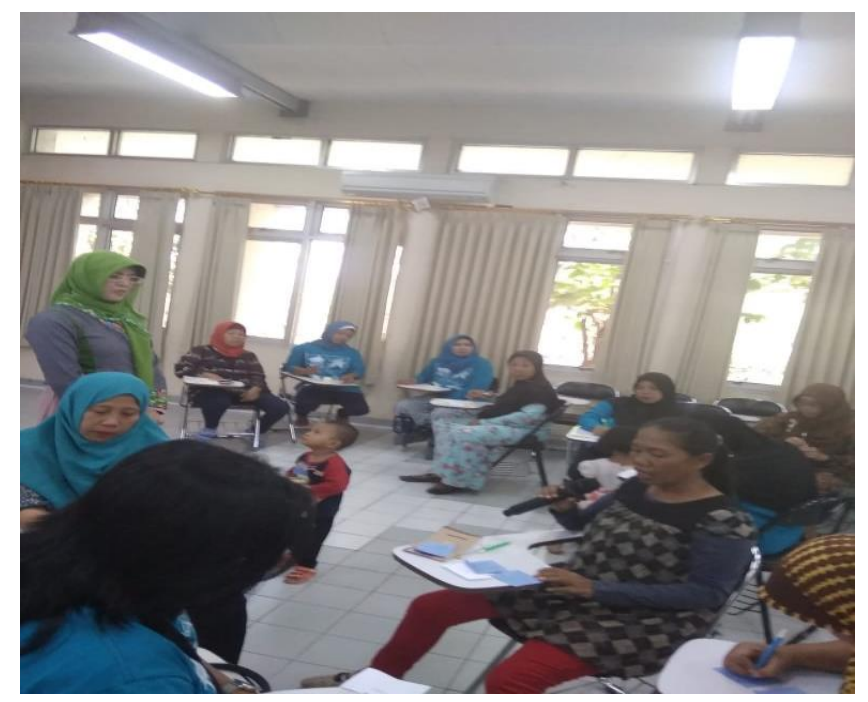

Gambar 2. Kegiatan Pelatihan

Kegiatan pelatihan telah dilakukan dan berjalan dengan baik. Dengan adanya kegiatan pelatihan, ibu-ibu merasa lebih paham dan jelas karena mereka mempraktikkan langsung apa yang sudah disampaikan pada saat penyuluhan. Pelatihan ini sangat berguna bagi ibu-ibu (peserta) karena menambah keterampilan ibu-ibu dalam memanfaatkan sampah menjadi suatu barang yang bernilai ekonomi serta menjaga kebersihan lingkungan sekitar. Asteria dan Haruman (2016), dalam penelitiannya mengatakan bahwa perlu pemberdayaan warga untuk membentuk pengetahuan dan keterampilan warga sehingga mampu memilah sampah organik 
dan non organik. Manfaat dari kemampuan warga mengelola sampah dengan menerapkan prinsip 4R yang memberikan manfaat langsung, tidak hanya secara ekonomi, juga terwujudnya kesehatan lingkungan, dengan kondisi komunitas yang bersih, hijau, nyaman, dan sehat.

Upaya-upaya untuk meningkatkan pengetahuan dan kesadaran untuk berpartisipasi mewujudkan konsep rumah ramah sampah masih perlu dilakukan. Kegiatan workshop dan pelatihan sebagai salah satu media pembelajaran seperti ini perlu dilakukan secara rutin agar literasi kesehatan masyarakat dapat meningkat. Dengan adanya workshop dan pelatihan ini, diharapkan dapat meningkatkan pengetahuan dan pemahaman serta keterampilan mengenai rumah ramah sampah, langkah-langkah konkrit, aplikatif, mudah diterapkan dan tidak memakan banyak biaya untuk menciptakan sebuah konsep rumah ramah sampah.

\section{SIMPULAN}

Pelaksanaan kegiatan pengabdian telah berjalan dengan lancar. Intervensi dilakukan dengan metode ceramah yaitu dengan kegiatan workshop, diskusi dan tanya jawab serta kegiatan pelatihan. Kegiatan ini dilasanakan dengan harapan dapat meningkatkan pengetahuan dan pemahaman serta keterampilan mengenai rumah ramah sampah, langkahlangkah konkrit, aplikatif, mudah diterapkan dan tidak memakan banyak biaya untuk menciptakan sebuah konsep rumah ramah sampah. Dalam pelaksanaan workshop ibu-ibu (peserta) berperan aktif dengan melakukan tanya jawab dan diskusi mengenai permasalahan yang terjadi saat ini berkatan dengan rumah ramah sampah atau pemanfaatan sampah. Pada saat kegiatan pelatihan, peserta dapat mempraktikan dengan baik ilmu yang mereka dapat serta menjadi wadah dalam menyalurkan kreativitas ibu-ibu. Adanya kegiatan workshop dan pelatihan ini dapat menjadi media promosi kesehatan yang diharapkan dapat berdampak pada peningkatan pengetahuan dan keterampilan masyarakat khususnya Ibu-ibu Komunitas Kalijawi dalam program penerapan rumah ramah sampah yang mempunyai manfaat dalam sektor ekonomi dan kesehatan lingkungan.

\section{DAFTAR PUSTAKA}

Asteria, D., Heruman, H. (2016). Bank sampah sebagai alternatif strategi pengelolaan sampah berbasis masyarakat di tasikmalaya. Jurnal Manusia dan Lingkungan. Vol: 23. No: 1. Hal: 136-141. 
Budiman. (2010). Ilmu kesehatan masyarakat dalam konteks kesehatan lingkungan. Buku Kedokteran EGC, Jakarta. Hal.129.

Notoatmodjo S. (2010). Ilmu perilaku kesehatan. Jakarta: PT Rineka Cipta

Nuraeni, A., Mirwanti R., Anastasia A. (2017). Upaya penegahan dan perawatan hipertensi di rumah melalui media pembelajaran bagi masyarakat di kabupaten pangandaran. Jurnal Pengabdian Kepada Masyarakat., 1(3), 174-178

Sudiran. (2005). Instrumen sosial masyarakat karangmumus kota samarinda dalam penanganan sampah domestik, Journal Makara, Sosial Humaniora, Vol.9, Hal. 16-17.

Sulistyorini, N. R., Rudi S. D., Arie S. G. (2015). Partisipasi masyarakat dalam pengelolaan sampah di lingkungan marguluyu kelurahan cicurug. Share Social Work Jurnal. Vol: 5. No: 1. Hal: 71-80.

Suwerda, B. (2012). Bank sampah kajian teori, Buku I. Yogyakarta: Werda Press. 
2018 Jurnal Pemberdayaan: Publikasi Hasil Pengabdian kepada Masyarakat - ISSN: 2088 4559; e-ISSN:

Penerapan Program Rumah Ramah Sampah (Surahma Asti Mulasari) | 478 